\title{
Obesity, The Single Most Important Risk Factor for OSA: A Case Report
}

\author{
Mamun SMAA ${ }^{1}$
}

\begin{abstract}
Obstructive sleep apnea (OSA) is characterized by repetitive airflow reduction caused by collapse of the upper airway during sleep in addition to daytime sleepiness, clinical symptoms include fatigue, insomnia, and snoring. The condition is associated with adverse clinical outcomes, including cardiovascular disease, hypertension, cognitive impairment, and metabolic abnormalities. ${ }^{1}$

Among the risk factors for OSA, obesity is probably the most important. Several studies have consistently found an association between increased body weight and risk of OSA.

Tomographic scanned images have shown that obesity causes increased fatty deposits in the pharyngeal area. $^{2}$

The deposits encroach on the airway and contribute to airway narrowing. Also, among obese patients as compared to normal controls, fat deposits appear to alter the shape of the upper airway without necessarily reducing the cross-sectional area. M. A. Ciscar et al used magnetic resonance imaging to investigate differences between obese and normal controls. ${ }^{2}$ Ultrafast magnetic resonance imaging was used to study the upper airway and surrounding soft tissue in 17 patients with OSA during wakefulness and sleep, and in eight healthy subjects whilst awake. Coronal sections of awake OSA patients showed elliptical-shaped airways with long axes that were oriented anteroposterior; normal controls had airways that were oriented transversely. Studies using computed tomography have produced similar results. $^{14}$
\end{abstract}

\section{Keywords}

Obstructive sleep apnea, Obesity, Apnea-hypopnea index

\section{Introduction}

Obesity is the most important risk factor for OSA, although people who aren't overweight can have OSA. Obesity increases the risk for sleep apnea because fatty tissue in breathing passage reduces the space for air to pass through. ${ }^{1}$

There is a dose-dependent relationship, with higher BMI indicating higher risk. A moderate to severe OSA category, defined by an Apneahypopnea Index $(\mathrm{AHI}) \geq 15$, was independently associated with increased BMI, neck circumference and waist circumference. ${ }^{1}$ Recently, patients with Diabetes Mellitus Type 2 and higher BMI were shown to be more likely to have severe OSA. ${ }^{4,15}$ 


\section{Case Report}

A 65-year-old male with a long-standing history of moderate snoring noted that, in recent years, the snoring had worsened so much that his wife banned him from their bedroom. Since his retirement at 60 , due to reduced physical activity he gained $20 \mathrm{~kg}$ and started suffering from knee problems. He noted increased fatigue, daytime sleepiness and some trouble in concentrating.

His current $\mathrm{BMI}=51.2 \mathrm{Kg} / \mathrm{sq}$. m. Arterial blood pressure was 120/75 $\mathrm{mmHg}$, pulse was $95 \mathrm{bpm}$, respiratory rate was $25 / \mathrm{min}$, and he had tachypnea. On respiratory system examination, there were both inspiratory\& expiratory rhonchi in all the lung fields. Other system examinations were normal.

Laboratory examinations were normal except for a mild anemia (Hemoglobin $=11.2$ gr) and serum $\operatorname{IgE}=181 \mathrm{IU} / \mathrm{ml}$. Chest X-Ray and spirometry revealed mild obstructive defect with positive reversibility to exclude an upper airway obstruction. Computed tomography (CT) of the thorax and paranasal sinuses and magnetic resonance imaging (MRI) of the neck, which were obtained to evaluate this, were normal. On ear-nose-throat and laryngoscopy examinations, the upper airway was normal. The patient was evaluated by the gastroenterology department to exclude gastroesophageal reflux disorder.

Bronchoscopy tests and transthoracic echocardiography of the patient revealed normal results. He noticed that he had been using meter dose inhaler properly for last 10 years as he was diagnosed as bronchial asthma. He reported that 10 years back he performed a polysomnography as suggested by his pulmonologist and it was normal. He is on medication regimen as treatment for Bronchial Asthma but he otherwise denied having any medical problems. He had a tonsillectomy in his childhood and had no history of thyroid disease.

Physical examination showed nasal congestion with moderately swollen, pale turbinate's and no purulent discharge. The septum was midline. Oropharyngeal examination showed no tonsils and a low soft palate with elongated uvula that tended to collapse against the posterior aspect of the pharynx and abutted the base of tongue. Fiber optic laryngeal examination showed a normal larynx with moderate collapse of the lateral pharyngeal walls in "blocked" inspiration (a reverse Müller's maneuver whereby the patient holds his nose, closes his mouth, and attempts to breathe inward).

He had a near normal neck and was overweight. The working diagnosis was obstructive sleep apnea after scoring with Epworth's score. ${ }^{17} \mathrm{~A}$ overnight sleep study was performed in our Sleep Lab including Oximetry and he was diagnosed as a case of severe obstructive sleep Apnea with AHI 51.

On next day of sleep test, patient started to use CPAP as per advice. On first night he was very much uncomfortable with the face mask and could use only 30 minutes and next morning come with concern. After proper counselling he went back home and came for follow up after one week. He was happy since he was able to enjoy a good sleep after many years. 
General and behavioral measures, such as weight loss, avoidance of alcohol for 4-6 hours prior to bedtime, and sleeping on one's side rather than on the stomach was advised. The best data suggest that a $10 \%$ reduction in weight leads to a $26 \%$ reduction in the respiratory disturbance index (RDI). ${ }^{13}$ Patient was also referred to dietician for proper dietary advice \& surgeon for consultation for bariatric surgery.

\section{Discussion}

Several risk factors, including obesity, male sex, age and heritable factors, have been associated with an increased prevalence of obstructive sleep apnea in the general population. ${ }^{1}$ Among these, obesity is one of the strongest sleep apnea risk factors. ${ }^{1}$ Young and colleagues ${ }^{3}$ showed that a 1-SD increase in BMI was associated with a four-fold increased risk for prevalent sleep apnea and they have demonstrated a sleep apnea prevalence of approximately $40 \%$ in moderately overweight men from the community who are otherwise healthy. ${ }^{4}$ In severe obesity (BMI $>40$ $\mathrm{kg} / \mathrm{m}^{2}$ ), the prevalence of sleep apnea was estimated to vary between $40 \%$ and $90 \% .^{5}$ In addition, Peppard and colleagues have provided further evidence for a link between sleep apnea and obesity by demonstrating that a $10 \%$ change in body weight was associated with a parallel change of approximately $30 \%$ in the apneahypopnea index (AHI), the major index of sleep apnea severity. ${ }^{5}$

Weight loss remains a highly effective strategy for treating sleep apnea. ${ }^{8}$ In two controlled studies, investigators have demonstrated that a $10 \%$ to $15 \%$ reduction in body weight leads to an approximately $50 \%$ reduction in sleep apnea severity (AHI) in moderately obese male patients. ${ }^{8}$ In recent years, bariatric surgical procedures have been increasingly used for the treatment of severe obesity.

Obesity is associated with anatomic alterations that predispose to upper airway obstruction during sleep. These alterations may result from adiposity around the pharynx and events as follows. First, increase in neck circumference and fat deposit around the upper airway. ${ }^{6}$ Second, upper airway collapsibility is higher in obese compared with non-obese individuals ${ }^{8}$ and does not decrease appropriately when the pharynx is dilated by advancing the mandible anteriorly. ${ }^{9}$ Third, obesity and especially central obesity have been associated with reductions in lung volume, ${ }^{10}$ which leads to a loss of caudal traction on the upper airway and an increase in pharyngeal collapsibility, ${ }^{11}$ increasing continuous positive airway pressure requirements ${ }^{12}$ and a greater severity of sleep apnea. ${ }^{13}$ Thus, obesity imposes mechanical loads on both the upper airway and respiratory system that predispose to upper airway narrowing, collapse and airflow obstruction during sleep. Although central adiposity is associated with structural defects that compromise airway patency, the mechanisms causing these elevations in upper airway mechanical loads in obesity are not well understood.

\section{Conclusion}

Improvements in sleep apnea with weight loss have been related to effects of adiposity on upper airway function during sleep. In controlled weight loss intervention studies, we demonstrated decreases in upper airway collapsibility during sleep with weight loss. ${ }^{8}$

Central obesity accounts for the strong male predominance of this disorder, whereas peripheral adiposity may protect women from developing 
adiposity may protect women from developing sleep apnea. Obesity and particularly central adiposity can increase sleep apnea susceptibility by increasing upper airway mechanical loads and/or decreasing compensatory neuromuscular responses. These effects may be mediated by circulating adipokines, ${ }^{16}$ which influence body fat distribution and CNS activity. As patients with sleep apnea lose weight, improvements in upper airway function and disease severity are likely related to the amount and patterns of weight loss as well as relative changes in protective and pathogenic adipokines. ${ }^{16}$

\section{References}

1. Rossini GJ. Obstructive Sleep Apnea and Obesity. Journal of Lancaster General Hospitals Winter, 2009; 4(4): 139-41.

2. Ciscar MA, Juan G, Martínez V, Ramón M, Lloret T, Mínguez J, et al. Magnetic resonance imaging of the pharynx in OSA patients and healthy subjects. European Respiratory Journal, 2001; 17:79-86

3. Young T, Palta M, Dempsey J, Skatrud J, Weber S, Badr S. The occurrence of sleep-disordered breathing among middleaged adults. N Engl J Med, 1993; 328(17):1230-5.

4. Punjabi NM, Sorkin JD, Katzel LI, Goldberg AP, Schwartz AR and Smith PL. Sleep-disordered breathing and insulin resistance in middle-aged and overweight men. Am J Respir Crit Care Med, 2002; 165:677-82.

5. Peppard PE, Young T, Palta M, Dempsey J, Skatrud J. Longitudinal study of moderate weight change and sleepdisordered breathing. JAMA, 2000; 284(37):3015-21.

6. Davies RJ, Stradling JR. The relationship between neck circumference, radiographic pharyngeal anatomy, and the obstructive sleep apnoea syndrome. Eur Respir J, 1990; 3:509-14.
7. Rajala R, Partinen M, Sane T, Pelkonen R, Huikuri K and Seppalainen AM. Obstructive sleep apnoea syndrome in morbidly obese patients. J Intern Med, 1991; 230(2):125-9.

8. Schwartz AR, Gold AR, Schubert N, Stryzak A, Wise RA, Permutt S, et al. Effect of weight loss on upper airway collapsibility in obstructive sleep apnea. Am Rev Respir Dis, 1991; 144:494-8.

9. Isono S, Tanaka A, Tagaito Y, Sho Y, Nishino T. Pharyngeal patency in response to advancement of the mandible in obese anesthetized persons. Anesthesiology, 1997; 87(5):1055-62.

10. Sharp JT, Henry JP, Sweany SK, Meadows WR and Pietras RJ. Effects of mass loading the respiratory system in man. J Appl Physiol, 1964; 19:959-66.

11. Thut DC, Schwartz AR, Roach D, Wise RA, Permutt S and Smith PL. Tracheal and neck position influence upper airway airflow dynamics by altering airway length. J Appl Physiol, 1993;75:2084-90.

12. Heinzer RC, Stanchina ML, Malhotra A, Fogel RB, Patel $\mathrm{SR}$, Jordan AS, et al. Lung volume and continuous positive airway pressure requirements in obstructive sleep apnea. Am J Respir Crit Care Med, 2005; 172(1):114-7.

13. Brown IG, Bradley TD, Phillipson EA, Zamel N, Hoffstein V. Pharyngeal compliance in snoring subjects with and without obstructive sleep apnea. Am Rev Respir Dis, 1985; 132(2):211-5.

14 Lowe AA, Fleetham JA, Adachi S, Ryan CF. Cephalometric and computed tomographic predictor of obstructive sleep apnea severity. Am J Orthod Dentofacial Orthop, 1995; 107:589-95.

15 Foster GD, Borradaile KE, Sanders MH, Millman R, Zammit G, Newman AB, et al. A randomized study on the effect of weight loss on Obstructive Sleep Apnea among Obese Patients with Type 2 Diabetes. Arch Int med, 2009; 169(17):1619-26

16. Zachariah JP, Hwang S, Hamburg NM, Benjamin EJ, Larson MG, Levy D, et al. Circulating Adipokines and Vascular Function: Cross-sectional Association in a CommunityBased Cohort. Hypertension. 2016; 67(2):294-300

17 Johns MW. Sleep propensity varies with behaviour and the situation in which it is measured: the concept of somnificity. $\mathrm{J}$ Sleep Res, 2002; 11: 61-7. 